\title{
Omni-directional Dual-Band Patch Antenna for the LMDS and WiGig Wireless Applications
}

\author{
Mourad S. Ibrahim ${ }^{1,2, *}$ \\ ${ }^{1}$ Department of Communications and Networks Engineering, College of Engineering, Prince Sultan University, Riyadh, 11586, KSA \\ ${ }^{2}$ College of Engineering, Modern Sciences and Arts University, $6^{\text {th }}$ October City. Egypt.
}

\begin{tabular}{l} 
A R T I C L E I N F O \\
\hline Article history: \\
Received: 20 September, \\
Accepted: 16 November, \\
Online: 23 December, 20 \\
\hline Keywords: \\
Dual band \\
Fifth generation \\
LMDS \\
Omnidirectional pattern \\
WiGig
\end{tabular}

\section{Introduction}

This paper is an extension of work originally presented in ACES [1]. More analysis and parametric studies have been done. The average data per person uses in telecommunication is rapidly increases over the past three decades [2]. This increase is more noticeable mostly with the outgrowth of the wireless communications. The main requirements for wireless communications are the ability to develop a low-cost, light-weight, and low-profile antennas to maintain good performance along a large bandwidth [2].

The shortage in the available global bandwidth has stimulated the reconnaissance of the under-utilized millimeter wave frequency band for the future wireless communications [3].

Multiband antennas have massive applications in millimeter band applications. A various techniques in the literature have been developed for multiband microstrip antennas as in [4-12]. For instance, a multilayer GaAs is described in [4] to achieve a multiband antenna operating at $35 \mathrm{GHz}$. In [5], two bands with less than $1.2 \%$ bandwidth with gains of $-9 \mathrm{dBi}$ and $1 \mathrm{dBi}$ at $24 \mathrm{GHz}$ band and $60 \mathrm{GHz}$ band respectively is presented. A dual band antenna at $41 \mathrm{GHz} / 52.2 \mathrm{GHz}$ using a meta-resonator with pair of

*Mourad S. Ibrahim, Riyadh 11586, mrizk@psu.edu.sa split ring resonators is introduced in [6] with bandwidth of $2 \%$, gain of $3.76 \mathrm{dBi}$, and efficiency of $71 \%$. In [7], two different modes are obtained to get a dual band at $58 \mathrm{GHz}$ and $77 \mathrm{GHz}$ with gains of $-2 \mathrm{dBi}$ and $0.3 \mathrm{dBi}$, respectively. The achieved bandwidths at both bands are nearly $6 \%$. A dual band centered at 24.5 and 35 $\mathrm{GHz}$ has been presented in [8] with only 1\% bandwidth and less than $2.8 \mathrm{dBi}$ gain using liquid crystal polymer. A coplanar hybrid dual band antenna at $83 \mathrm{GHz} / 94 \mathrm{GHz}$ with a slot in feeding line has been developed in [9]. In [10] an antenna array with Electromagnetic Band Gap [EBG] structure was used to develop a dual band at $28 / 38 \mathrm{GHz}$ with bandwidth of less than $5.8 \%$. A three layers of substrates have been used in [11] to design a Fabry-Perot cavity antenna operates at $36 \mathrm{GHz}$ with high gain. In [12], Lshaped slots have been used to obtain a dual band $28 / 38 \mathrm{GHz}$ slotted patch antenna.

In this paper, the design, optimization, and simulation of a monopole planar antenna are introduced. The antenna is optimized to operate at $\mathrm{Ka}$ - band $(28 \mathrm{GHz})$ for Local Multipoint Distribution Service (LMDS) which currently investigated for the fifth generation mobile cellular [13], and the $\mathrm{V}$ - band $(60 \mathrm{GHz})$ for Wireless Gigabit Alliance (WiGig) applications [14].

This paper is organized into four sections. Section 1 covers the introduction and literature review. Antenna structure and design is introduced in section 2. Parametric study of a dual band 
omnidirectional pattern circularly polarized wideband antenna is presented in section 3 . The simulation results are investigated in Section 4. Finally, the conclusion is presented in section 5.

\section{Antenna Geometry and Design}

Figure 1 shows the antenna geometry in perspective and top view. The proposed antenna patch consists of a T-folded shape with two rectangular patches and partially grounded [15]. The antenna gives wide bandwidth with improved antenna performance. The patch mounted on substrate FR-4 with a relative permittivity of 4.4. Figure 2 illustrates the whole antenna dimensions. The substrate dimension is $\mathrm{W}_{\mathrm{s}}$ by $\mathrm{L}_{\mathrm{s}}$ and the partial ground is $\mathrm{W}_{\mathrm{s}}$ by $\mathrm{L}_{\mathrm{g}}$. The dimensions of T-folded are $\mathrm{L}_{\text {top }}, \mathrm{L}_{\text {fold }}, \mathrm{L}_{\mathrm{t}}$ $\mathrm{W}_{\mathrm{t}}$ for top length, folded side length, mid length, and mid width. The two patches have dimensions of $\mathrm{W}_{\mathrm{p}}$ by $\mathrm{L}_{\mathrm{p}}$.

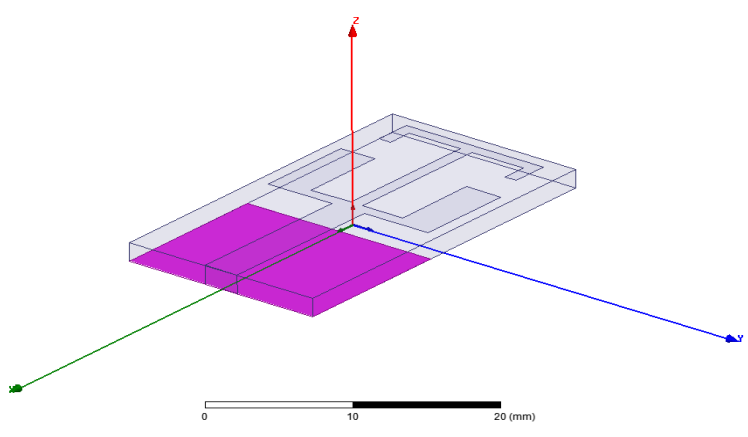

(a)

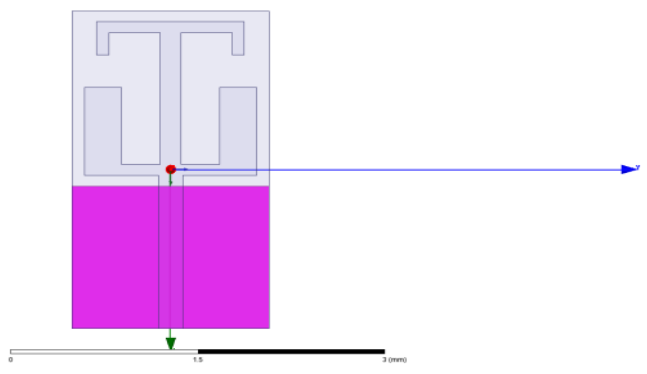

(b)

Figure1. Antenna geometry a) Perspective view b) Top view.

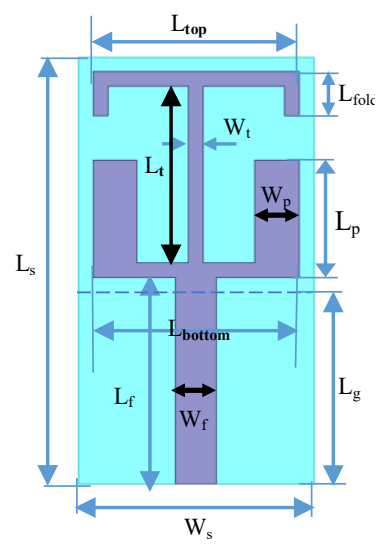

Figure 2. Antenna structure and dimensions.
The antenna feeding transmission line (TL) dimension is $\mathrm{W}_{\mathrm{f}}$ by $\mathrm{L}_{\mathrm{f}}$. The TL characteristic impedance can be calculated by the following formulas [16]:

When $\frac{\mathrm{W}}{\mathrm{h}} \leq 1$, the characteristic impedance is

$$
Z_{c}=\frac{60}{\sqrt{\varepsilon_{\text {reff }}}} \ln \left[\frac{8 h}{w}+\frac{w}{4 h}\right]
$$

where

$$
\varepsilon_{\text {reff }}=\frac{\varepsilon_{r}+1}{2}+\frac{\varepsilon_{r}-1}{2} \times\left\{\left[1+12 \frac{h}{w}\right]^{-1 / 2}+0.04\left[1-\frac{w}{h}\right]^{2}\right\}
$$

while when $\frac{\mathrm{w}}{\mathrm{h}}>1$

$$
Z_{c}=\frac{\frac{120 \pi}{\sqrt{\varepsilon_{\text {reff }}}}}{\frac{w}{h}+1.393+0.667 \ln \left[\frac{w}{h}+1.444\right]}
$$

where

$$
\varepsilon_{r e f f}=\frac{\varepsilon_{r}+1}{2}+\frac{\varepsilon_{r}-1}{2}\left[1+12 \frac{h}{w}\right]^{-1 / 2}
$$

In the formulas, $\mathrm{h}$ represents the substrate height, $\mathrm{w}$ represents the TL width, and $\varepsilon_{\text {reff }}$ represents the effective relative permittivity.

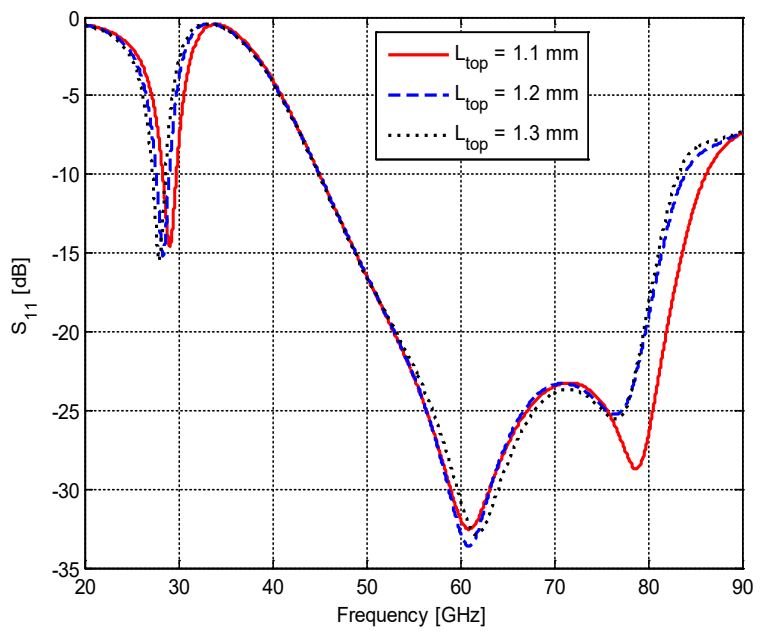

Figure. 3. The effect of changing $\mathrm{L}_{\text {top }}$ on $\mathrm{S}_{11}$.

\section{Parametric Study}

The effect of varying antenna dimensions $\mathrm{L}_{\text {fold }}, \mathrm{L}_{\text {top }}, \mathrm{L}_{\text {bottom, }} \mathrm{L}_{\mathrm{P}}$, $\mathrm{W}_{\mathrm{P}}$, and $\mathrm{L}_{\mathrm{t}}$ using HFSS are shown in figures 3 to 8 . The dimensions of the substrate, ground, and feeder are kept unchanged. With increasing $\mathrm{L}_{\text {top }}$ of the horizontal part of T-shaped, the lower resonant frequency is decreased with same bandwidth whereas the upper bandwidth is decreased as shown in Figure 3. Figure 4 illustrates the effect of varying $L_{\text {bottom }}$ on the return loss. As noted from the figure, by increasing the $\mathrm{L}_{\text {bottom, }}$ the lower resonant frequency almost unaltered whereas the resonant frequency of the 
upper band is increased with a little increase in the bandwidth. With increasing $\mathrm{W}_{\mathrm{P}}$, the upper and the lower resonant frequencies are almost unchanged as shown in Figure 5.

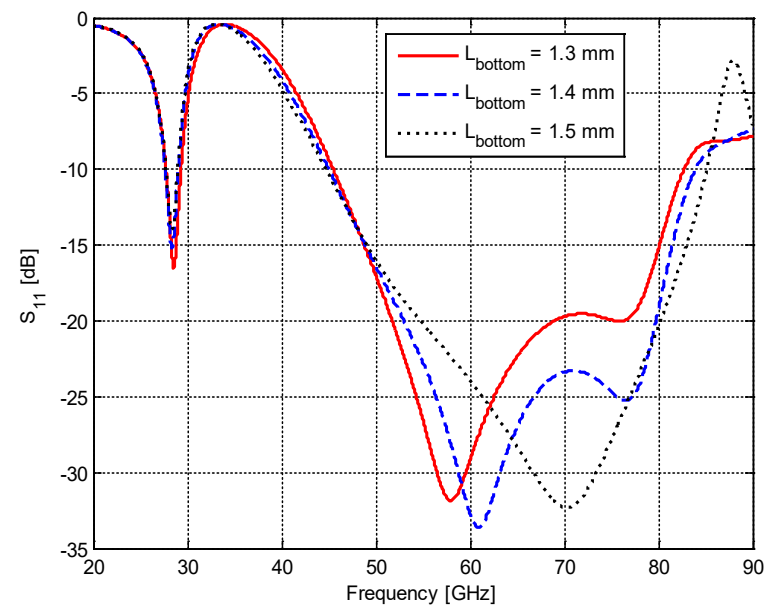

Figure. 4. The effect of changing $\mathrm{L}_{\text {bottom }}$ on $\mathrm{S}_{11}$.

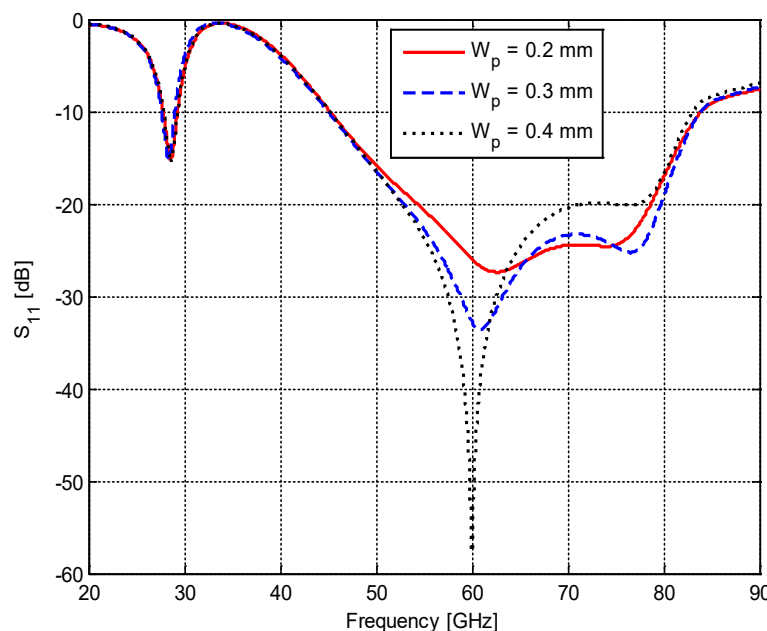

Figure. 5. The effect of changing $\mathrm{W}_{\mathrm{p}}$ on $\mathrm{S}_{11}$.

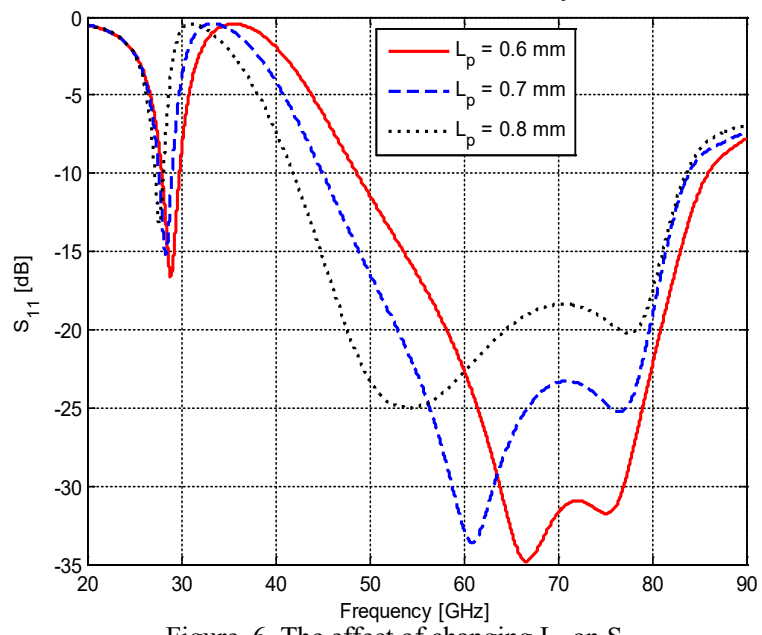

Figure. 6. The effect of changing $L_{p}$ on $S_{11}$.

As the length of rectangular patch $L_{P}$ increases, the upper and lower resonant frequency are decreased but the antenna matching becomes worse. Lower bandwidth is increases whereas the upper bandwidth is decreases as shown in Figure 6. Figure 7 illustrates the return loss varies with $L_{\text {fold. }}$ As $\mathrm{L}_{\text {fold }}$ increases the lower resonant frequency decreases while upper resonant frequency unchanged whereas the lower bandwidth is not affected, the upper bandwidth is a little decreases as shown in Figure 7. With increasing $\mathrm{L}_{\mathrm{t}}$, the lower and the upper resonant frequencies are not affected whereas the upper bandwidth is decreases, the lower bandwidth is unchanged as shown in Figure 8 .

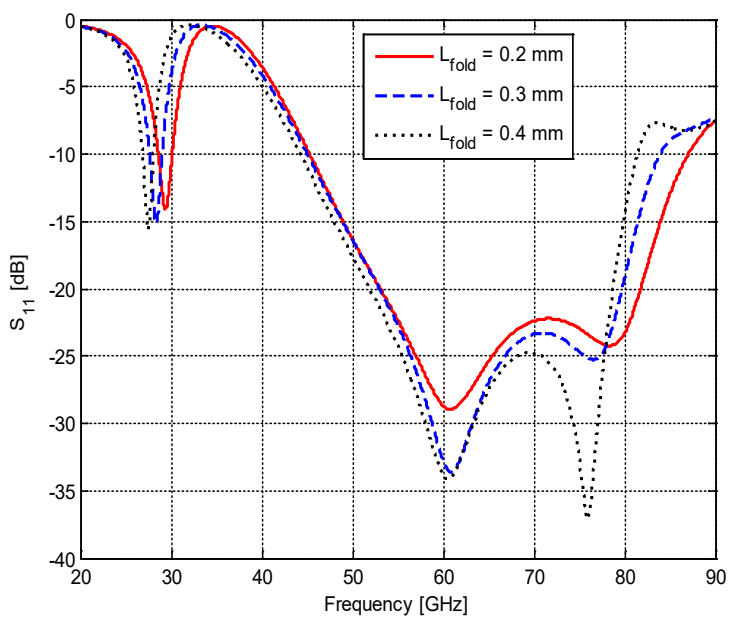

Figure. 7. The effect of changing $\mathrm{L}_{\text {fold }}$ on $\mathrm{S}_{11}$.

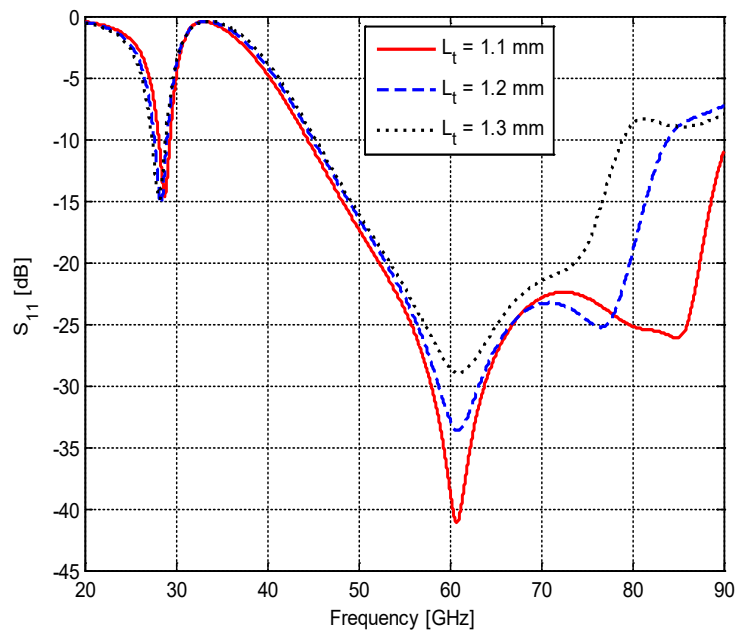

Figure. 8. The effect of changing $\mathrm{L}_{t}$ on $\mathrm{S}_{11}$.

\section{Antenna Simulation Results}

The antenna dimensions are optimized to obtain an Omnidirectional radiation patterns with acceptable performance at 28 $\mathrm{GHz}$ and $60 \mathrm{GHz}$. Table 1 contains the optimized dimensions for the proposed antenna in order to have a dual band.

The optimized antenna is simulated using two simulators based on FIT [17] and FEM [18] in order to validate the results. The $\mathrm{S}_{11}$ for the proposed antenna using FEM and FIT is shown in Figure 9. The FEM gives a better matching than FIT and the small deviation in the $60 \mathrm{GHz}$ band is due to the different mesh sizes. As can be noted from Figure 9, the antenna well matched over the two bands and the impedance bandwidth for which $\mathrm{S}_{11} \leq-10 \mathrm{~dB}$ in $28 \mathrm{GHz}$ band is extended from $27.52 \mathrm{GHz}$ to $28.96 \mathrm{GHz}$ which 
serves the LMDS band and in $60 \mathrm{GHz}$ band is extended from 45.2 $\mathrm{GHz}$ to $84.4 \mathrm{GHz}$ which serves the WiGig band.

Table 1: Dimensions of the proposed antenna in $\mathrm{mm}$.

\begin{tabular}{|c|c|c|c|}
\hline Parameter & Value & Parameter & Value \\
\hline $\mathrm{W}_{\mathrm{s}}$ & 1.6 & $\mathrm{~W}_{\mathrm{p}}$ & 0.3 \\
\hline $\mathrm{L}_{\mathrm{s}}$ & 2.9 & $\mathrm{~L}_{\mathrm{p}}$ & 0.7 \\
\hline $\mathrm{L}_{\mathrm{g}}$ & 1.3 & $\mathrm{~W}_{\mathrm{t}}$ & 0.1 \\
\hline $\mathrm{W}_{\mathrm{f}}$ & 0.2 & $\mathrm{~L}_{\mathrm{t}}$ & 1.2 \\
\hline $\mathrm{L}_{\mathrm{f}}$ & 1.4 & $\mathrm{~L}_{\text {top }}$ & 1.2 \\
\hline $\mathrm{L}_{\text {fold }}$ & 0.3 & $\mathrm{~L}_{\text {bottom }}$ & 1.4 \\
\hline
\end{tabular}

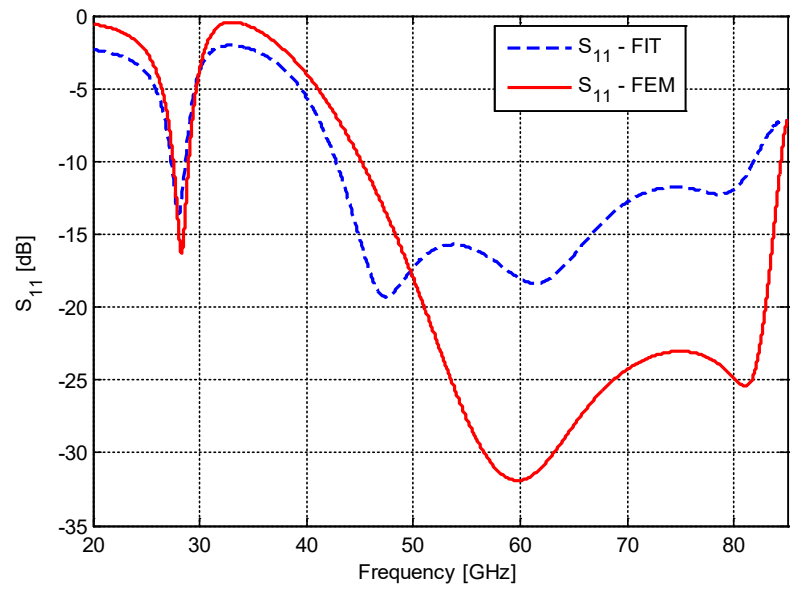

Figure. 9. Comparison of $\mathrm{S}_{11}$ for the optimized antenna by FIT and FEM.

The antenna resonates at $28.24 \mathrm{GHz}$ with $1.44 \mathrm{GHz}$ bandwidth $(5.1 \%)$ and at $64.76 \mathrm{GHz}$ with wide bandwidth of $39.24 \mathrm{GHz}(60.6 \%)$. The VSWR is shown in Figure 10 with VSWR $\leq 2$ using FIT and FEM in the entire bandwidths of both bands.

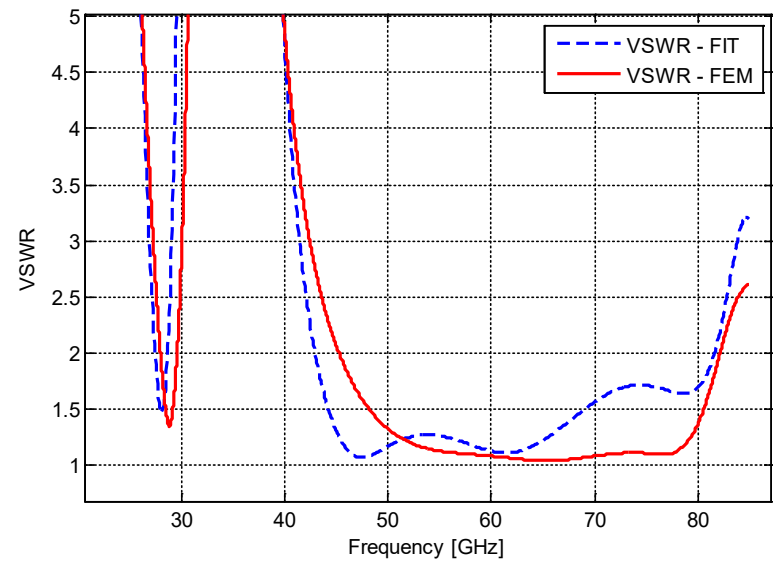

Figure. 10. VSWR using FIT and FEM.

The antenna real and imaginary input impedance for the proposed antenna is illustrated in Figure. 11. As can be noted from Figure 11, the antenna is well matched to $50 \Omega$ TL since the real part of the input impedance is approximately $50 \Omega$ while the imaginary part tends to zero along the entire bandwidths of both bands.
The radiation patterns at $28 \mathrm{GHz}$ and $60 \mathrm{GHz}$ are illustrated in Figure 12. The directivity pattern at $28 \mathrm{GHz}$ with $\mathrm{D}_{\mathrm{o}}$ of $2.28 \mathrm{dBi}$ is illustrated in Figure 12(a) and at $60 \mathrm{GHz}$ with $\mathrm{D}_{0}$ of $3.41 \mathrm{dBi}$ is shown in Figure 12(b). The total antenna efficiency along the lower band is $93 \%$ while along the upper band is $85.5 \%$.

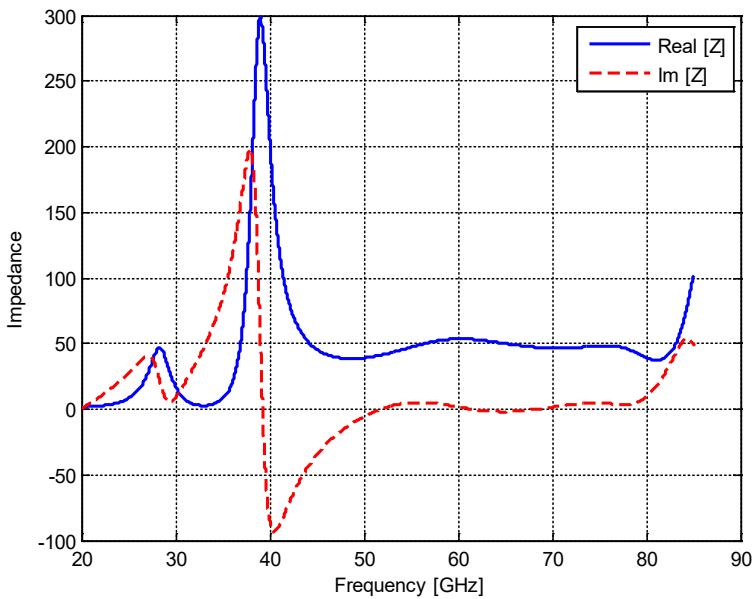

Figure. 11. The real and imaginary part of input impedance for the proposed antenna.

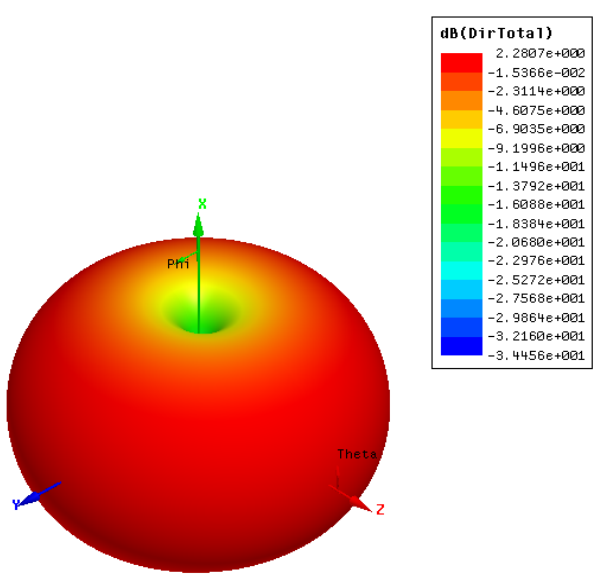

(a)

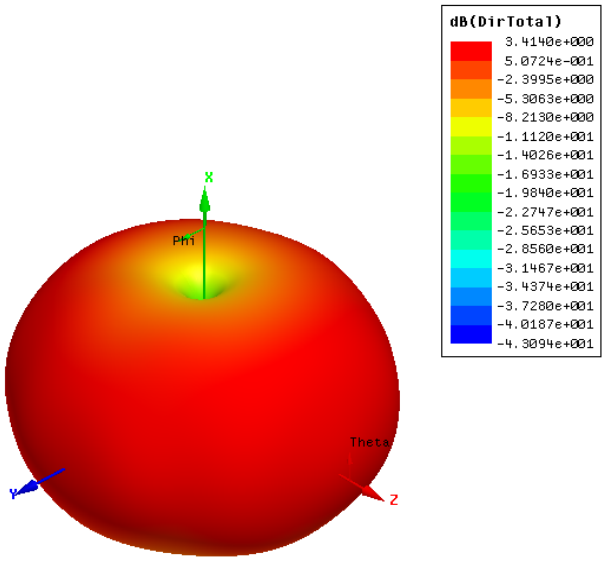

(b)

Figure 12 . The directivity patterns at a) $28 \mathrm{GHz}\left(\mathrm{D}_{\mathrm{o}}=2.28 \mathrm{dBi}\right)$ and at b) 60 $\mathrm{GHz}\left(\mathrm{D}_{0}=3.4 \mathrm{dBi}\right)$. 


\section{Conclusion}

In this paper, antenna with two rectangular patches and a Tshaped folded patch is designed, optimized, and simulated. The antenna exhibits two bands resonate at $28.24 \mathrm{GHz}$ and $64.76 \mathrm{GHz}$ with bandwidths of $1.44 \mathrm{GHz}(5.1 \%)$, and $39.24 \mathrm{GHz}$ $(60.6 \%)$ respectively. The lower band (Ka-band) is suitable for LMDS while the upper band (V-band) with wideband is suitable for WiGig. The omnidirectional radiation pattern is obtained using partial ground plane with maximum directivities of $2.28 \mathrm{dBi}$ and $3.414 \mathrm{dBi}$ at the two bands respectively. The total efficiency along the entire lower and upper bands exceeds $85 \%$ which can be used in the fifth generation applications.

\section{Acknowledgment}

The author gratefully acknowledges the support of Prince Sultan University.

\section{References}

[1] M. S. Ibrahim, "Dual-band microstrip antenna for the fifth generation indoor/outdoor wireless applications," in 2018 International Applied Computational Electromagnetics Society Symposium (ACES), 2018, pp. 1-2.

[2] S. S. Jaco du Preez, Millimeter-Wave Antennas: Configurations and Applications: Springer International Publishing Switzerland, 2016.

[3] T. S. Rappaport, S. Sun, R. Mayzus, H. Zhao, Y. Azar, K. Wang, G. N. Wong, J. K. Schulz, M. Samimi, and F. Gutierrez, "Millimeter Wave Mobile Communications for 5G Cellular: It Will Work!," IEEE Access, vol. 1, pp. 335-349, 2013.

[4] D. Sanchez-Hernandez, Q. H. Wang, A. A. Rezazadeh, and I. D. Robertson, "Millimeter-wave dual-band microstrip patch antennas using multilayer GaAs technology," IEEE Transactions on Microwave Theory and Techniques, vol. 44, pp. 1590-1593, 1996.

[5] H. Jie-Huang, W. Jin-Wei, C. Yi-Lin, and C. F. Jou, "A 24/60GHz dual-band millimeter-wave on-chip monopole antenna fabricated with a $0.13-\mu \mathrm{m}$ CMOS technology," in 2009 IEEE International Workshop on Antenna Technology, pp. 1-4, 2009.

[6] I. K. Kim and V. V. Varadan, "Electrically Small, Millimeter Wave Dual Band Meta-Resonator Antennas," IEEE Transactions on Antennas and Propagation, vol. 58, pp. 3458-3463, 2010.

[7] T. Y. Lin, T. Chiu, and D. C. Chang, "Design of Dual-Band Millimeter-Wave Antenna-in-Package Using Flip-Chip Assembly," IEEE Transactions on Components, Packaging and Manufacturing Technology, vol. 4, pp. 385391, 2014.

[8] D. Lee and C. Nguyen, "A millimeter-wave dual-band dual-polarization antenna on liquid crystal polymer," in 2014 IEEE Antennas and Propagation Society International Symposium (APSURSI), pp. 775-776, 2014.

[9] S. Agarwal, N. P. Pathak, and D. Singh, "Concurrent $83 \mathrm{GHz} / 94 \mathrm{GHz}$ parasitically coupled defected microstrip feedline antenna for millimeter wave applications," in 2013 IEEE Applied Electromagnetics Conference (AEMC), pp. 1-2, 2013.

[10] N. Ashraf, O. Haraz, M. A. Ashraf, and S. Alshebeili, "28/38-GHz dual-band millimeter wave SIW array antenna with EBG structures for 5G applications," in 2015 International Conference on Information and Communication Technology Research (ICTRC), pp. 5-8, 2015.

[11] G. N. Tan, X. X. Yang, and B. Han, "A dual-polarized Fabry-Perot cavity antenna at millimeter wave band with high gain," in 2015 IEEE 4th AsiaPacific Conference on Antennas and Propagation (APCAP), pp. 621-622, 2015.

[12] H. Aliakbari, A. Abdipour, R. Mirzavand, A. Costanzo, and P. Mousavi, "A single feed dual-band circularly polarized millimeter-wave antenna for $5 \mathrm{G}$ communication," in 2016 10th European Conference on Antennas and Propagation (EuCAP), pp. 1-5, 2016.

[13] S. Hur, S. Baek, B. Kim, Y. Chang, A. F. Molisch, T. S. Rappaport, K. Haneda, and J. Park, "Proposal on Millimeter-Wave Channel Modeling for 5G Cellular System," IEEE Journal of Selected Topics in Signal Processing, vol. 10, pp. 454-469, 2016.

[14] C. J. Hansen, "WiGiG: Multi-gigabit wireless communications in the 60 GHz band," IEEE Wireless Communications, vol. 18, pp. 6-7, 2011.
[15] W. H. Yang J., Lv Z., Wang H., "Design of miniaturized dual-band microstrip antenna for WLAN application," Sensors, vol. 16, pp. 1-15, 2016.

[16] C. A. Balanis, Advanced Engineering Electromagnetics, Second Edition ed.: JohnWiley \& Sons, New York, 2012.

[17] (2015) CST Microwave Studio. Available: https://www.cst.com/products/cstmws

[18] High Frequency Surface Structure (HFSS) (15 ed.). Available: http://www.ansys.com 